\title{
Identifikasi Pola Suara Pada Bahasa Jawa Meggunakan Mel Frequency Cepstral Coefficients (MFCC)
}

\author{
Istian Kriya Almanfaluti, Judi Prajetno Sugiono \\ Fakultas Sains dan Teknologi, Teknologi Informasi, Institut Sains dan Teknologi Terpadu Surabaya, Surabaya, Indonesia \\ Email: ${ }^{1}$ istian.alman@gmail.com, ${ }^{2}$ jpsugiono@stts.edu \\ *) Email Penulis Korespondensi: istian.alman@gmail.com
}

\begin{abstract}
Abstrak-Pengenalan Suara adalah suatu proses pengembangan sistem yang digunakan antara komputer dan manusia. Tujuan dari penelitian ini adalah untuk mengetahui pola suara dari seseorang berdasarkan kata bahasa jawa yang diucapkan. Penelitian ini menggunakan metode Mel Frequency Cepstral Coefficients (MFCC) untuk menyelesaikan masalah ekstraksi ciri dari suara manusia. Pengujian dilakukan pada 4 pengguna yang terdiri dari 2 perempuan dan 2 laki-laki, masing-masing mengucapkan 1 buah kata "KUTHO", kata diucapkan sebanyak 5 kali. Hasil dari pengujian yakni mendapatkan pola suara dari ciri 1 orang dengan orang yang lain sehingga penelitian dengan metode MFCC dapat menghasilkan pola suara yang berbeda.
\end{abstract}

Kata Kunci: Suara, Pola Suara, MFCC, Bahasa Jawa, ISTTS

Abstract-Voice Recognition is a process of developing systems used between computer and human. The purpose of this study is to find out the sound pattern of a person based on the spoken Javanese language. This study used the Mel Frequency Cepstral Coefficients (MFCC) method to solve the problem of feature extraction from human voices. Tests were carried out on 4 users consisting of 2 women and 2 men, each saying 1 word "KUTHO", the word pronounced 5 times. The results of the testing are to get a sound pattern from the characteristics of 1 person with another person so that research using the MFCC method can produce different sound patterns.

Keywords: Voice, Voice Pattern, MFCC, Javanese, ISTTS

\section{PENDAHULUAN}

Pengenalan Suara merupakan salah satu pengembangan bidang aplikasi yang memungkinkan suatu perangkat lunak mampu mencocokkan pola sinyal digital sehingga mampu mengenali kata tertentu dalam suatu perangkat. Kata yang diucapkan dikonversi menjadi sinyal digital dengan cara mengubah gelombang suara menjadi sekumpulan angka yang kemudian disesuaikan dengan kode-kode tertentu untuk mengidentifikasi kata- kata tersebut.

Metode mengetahui identitas seseorang bermacam - macam diantaranya berdasarkan karakter fisik adalah wajah (face recognition), sidik jari (fingerprint), struktur telapak tangan, retina mata (iris), suara (voice recognition)[1]. Tantangan besar yang dihadapi dalam sistem komunikasi antara mesin dan manusia adalah kemampuan komputer untuk memahami suatu karakter suara dari pembicara dengan berbagai latar belakang budaya, bahasa ibu ataupun jenis kelamin pembicara[2].

Adanya sebuah pendekatan teknologi ini juga membantu menjalankan salah satu fungsi Direktorat Jendral Kebudayaan yang diatur dalam pasal 473 yaitu pemberian bimbingan teknis dan supervisi di bidang kebudayaan, perfilman, kesenian, sejarah, cagar budaya, permuseuman, warisan budaya, dan kebudayaan lainnya[3]. Hasil dari pengenalan pola suara banyak digunakan pada identifikasi objek dengan perintah suara[4], system control pada smart home[5], aplikasi suara ke text[6], sistem automasi rumah[7], identifikasi nada[8], sistem pengenal penutur[9], sistem verifikasi suara[10] dan pengenalan pola ciri emosi manusia[11]

Tujuan penelitian untuk memberikan gambaran bentuk pola seseorang sehingga dapat dilihat perbedaan pola dari setiap seseorang. Metode ekstraksi ciri yang digunakan pada penelitian ini adalah dengan Mel Frequency Cepstral Coefficients (MFCC)

\section{METODE PENELITIAN}

Penelitian ini menggunakan Dataset yang merupakan hasil rekaman suara yang melibatkan 4 suara ucapan dari 4 orang, 2 pria dan 2 wanita. Kata yang dipilih adalah kata "KUTHO” Pengucapan kata bahasa jawa akan dilakukan 5 kali per orang. Langkah pertama ialah melakukan pre-processing pada rekaman suara yaitu dengan melakukan pemotongan rekaman suara tiap pengguna sebagai sampling.

Tujuan dari sampling adalah agar pola suara terlihat untuk masing-masing pengguna, serta mengubah sampel suara tiap pengguna dalam bentuk .wav menggunakan software audacity. Tahapan selanjutnya data sampel diproses menggunakan metode ekstraksi ciri suara dengan MFCC, hasil ekstraksi ciri diperoleh 13 ciri MFCC untuk setiap data suara pengguna.

Kumpulan data yang telah diekstrak dicari nilai koefisien maksimal dan minimal tiap pengguna. Tahapan ini merupakan hasil dari ekstraksi ciri suara pengguna menggunakan MFCC yang selanjutnya ditampilkan dalam bentuk grafik untuk mengetahui pola suara pengguna pada suara bahasa jawa. Proses Penelitian pengenalan pola suara pada bahasa jawa secara umum dapat dilihat pada gambar 1 . 


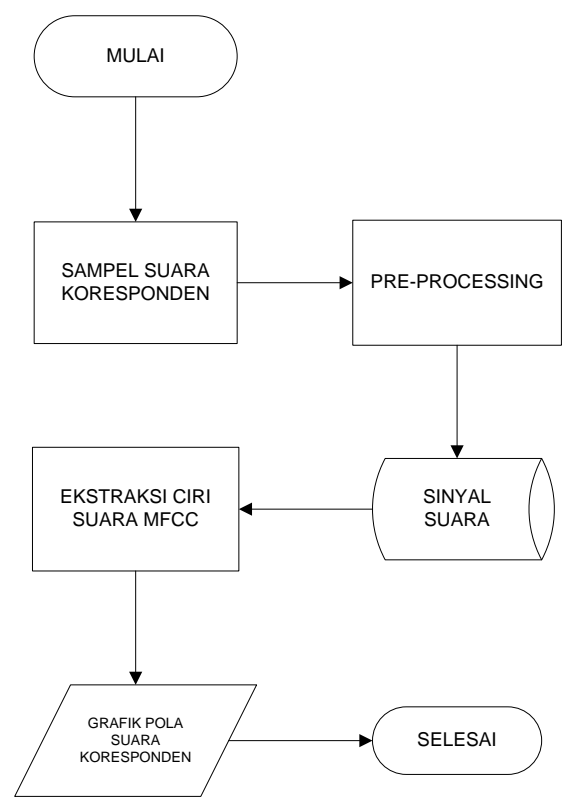

Gambar 1. Alur Penelitian

\section{HASIL DAN PEMBAHASAN}

Pengujian dilakukan untuk mengetahui pola suara pada bahasa jawa dimana menggunakan ekstraksi ciri MFCC dengan beberapa parameter-parameter untuk menghasilkan bentuk pola suara koresponden. Beberapa parameter yang digunakan yaitu $\mathrm{Tw}=25$; sebagai durasi frame $(\mathrm{ms}), \mathrm{Ts}=10$; sebagai pergeseran frame $(\mathrm{ms})$, Alpha = 0,97; sebagai nilai koefisien preemphasis, $M=24$; sebagai nilai filterbank, $C=13$; sebagai nilai cepstral coefficients.

Proses ekstraksi ciri ini menggunakan software matlab 2012. Kemudian dari proses ekstraksi ciri menghasilkan 13 ekstraksi ciri dari tiap sampel suara yang diucapkan oleh koresponden, hasil ekstraksi ciri salah satu koresponden ditunjukkan pada tabel 1

Tabel 1. Hasil ekstraksi ciri suara adit

\begin{tabular}{cccccc}
\hline MFCC & S1 & S2 & S3 & S4 & S5 \\
\hline CH1 & 6,4954 & 7,6699 & 5,4601 & 6,5062 & 6,1677 \\
CH2 & 2,7526 & 3,671 & 1,9896 & 2,5872 & 2,5373 \\
CH3 & $-4,8112$ & $-4,303$ & $-3,1915$ & $-4,5618$ & $-3,9869$ \\
CH4 & $-8,4273$ & $-9,4305$ & $-5,7502$ & $-7,7316$ & $-7,4705$ \\
CH5 & $-2,0379$ & $-4,6771$ & $-1,6527$ & $-1,6005$ & $-2,4423$ \\
CH6 & 5,8739 & 3,4571 & 3,4077 & 5,2828 & 4,4973 \\
CH7 & 5,4908 & 5,4186 & 3,2078 & 4,2652 & 4,9453 \\
CH8 & $-0,1588$ & 1,8656 & 0,0493 & $-0,6853$ & 0,6302 \\
CH9 & $-2,4549$ & $-0,6256$ & $-0,8322$ & $-1,7903$ & $-1,6133$ \\
CH10 & $-0,6194$ & $-0,388$ & 0,2725 & 0,2486 & $-0,6305$ \\
CH11 & 0,4858 & $-0,1045$ & 0,2863 & 0,6493 & 0,1082 \\
CH12 & $-0,1645$ & $-0,4$ & $-0,5097$ & $-0,3989$ & $-0,2819$ \\
CH13 & $-0,2834$ & $-0,1971$ & $-0,3371$ & $-0,352$ & $-0,2425$ \\
\hline
\end{tabular}

Setelah proses ekstraksi suara serta mengetahui bentuk pola suara koresponden. Maka langkah terakhir adalah mencari nilai maksimal dan minimal koefisien dari 13 ciri dapat dilihat pada tabel 2

Tabel 2. Nilai maksimal dan minimal koefisien koresponden adit

\begin{tabular}{cccccc}
\hline Koef & S1 & S2 & S3 & S4 & S5 \\
\hline Max & 6,4954 & 7,6699 & 5,4601 & 6,5062 & 6,1677 \\
\multirow{2}{*}{ Min } & $-8,4273$ & $-9,4305$ & $-5,7502$ & $-7,7316$ & $-7,4705$ \\
\hline
\end{tabular}


Available Online at https://ejurnal.stmik-budidarma.ac.id/index.php/mib DOI 10.30865/mib.v4i1.1793 gambar 2

Tabel 2 merupakan hasil dari ekstraksi ciri koresponden, sehingga didapat bentuk pola suara seperti pada

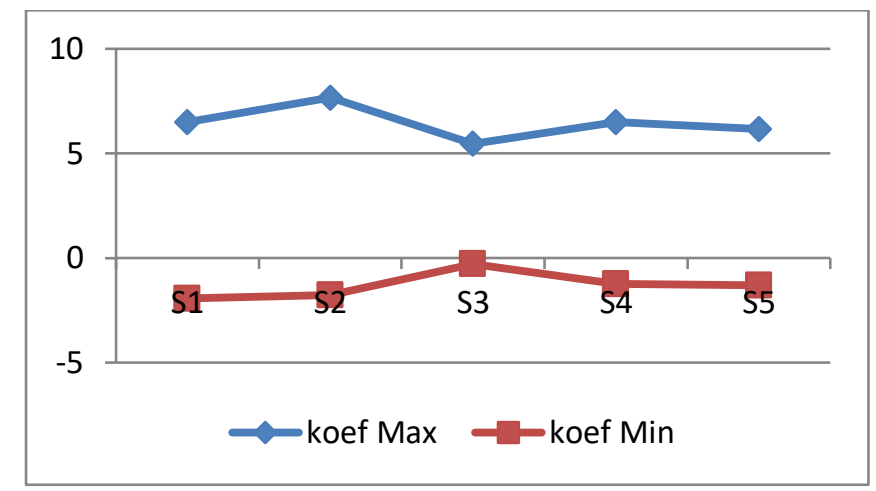

Gambar 2. Bentuk Sampel Pola Suara Kutho Koresponden Adit

Hasil koefisien maksimal dan minimal serta grafik pola 4 pengguna ditunjukkan pada gambar 3 sampai 6 dan tabel 3 sampai 6

Tabel 3. Nilai maksimal dan minimal koefisien pengguna adit

\begin{tabular}{cccccc}
\hline Koef & S1 & S2 & S3 & S4 & S5 \\
\hline Max & 6,4954 & 7,6699 & 5,4601 & 6,5062 & 6,1677 \\
Min & $-8,4273$ & $-9,4305$ & $-5,7502$ & $-7,7316$ & $-7,4705$ \\
\hline
\end{tabular}

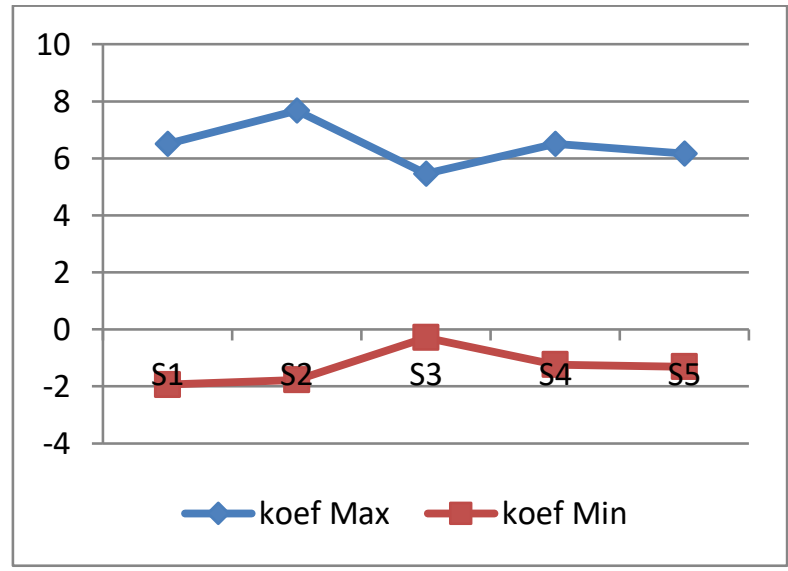

Gambar 3. Bentuk Sampel Pola Suara Kutho Pengguna Adit

Tabel 4. Nilai maksimal dan minimal koefisien pengguna istian

\begin{tabular}{cccccc}
\hline Koef & S1 & S2 & S3 & S4 & S5 \\
\hline Max & 6,9457 & 7,2221 & 5,6686 & 9,6178 & 7,2901 \\
Min & $-8,851$ & $-6,9039$ & $-5,9728$ & $-9,215$ & $-10,0987$ \\
\hline
\end{tabular}

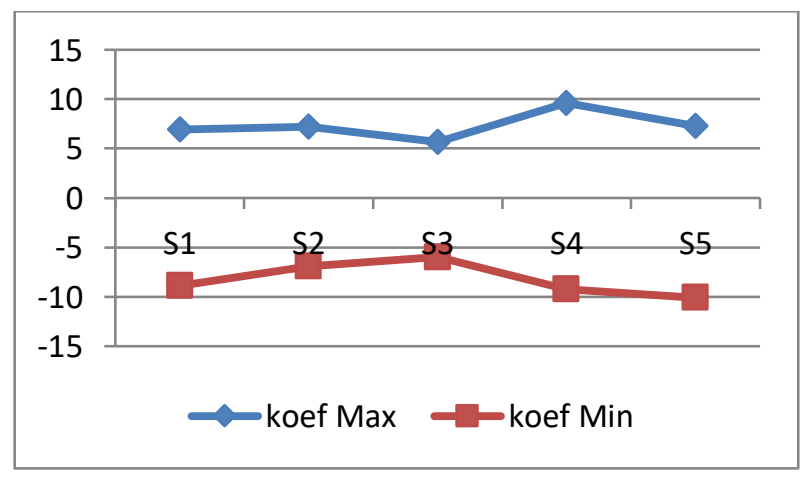

Gambar 4. bentuk sampel pola suara kutho pengguna istian 
Available Online at https://ejurnal.stmik-budidarma.ac.id/index.php/mib DOI 10.30865/mib.v4i1.1793

Tabel 5. Nilai maksimal dan minimal koefisien pengguna Irma

\begin{tabular}{cccccc}
\hline Koef & S1 & S2 & S3 & S4 & S5 \\
\hline Max & 8,3737 & 6,7633 & 7,0033 & 6,1014 & 6,7347 \\
Min & $-7,2375$ & $-4,744$ & $-5,7577$ & $-1,5675$ & $-2,7153$ \\
\hline
\end{tabular}

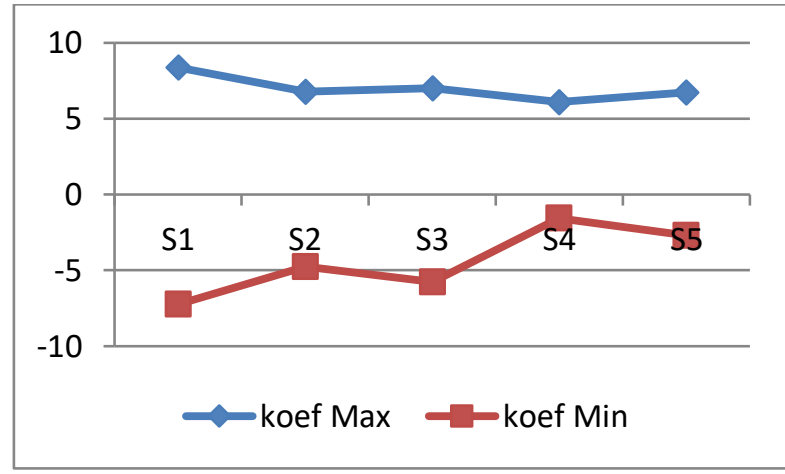

Gambar 5. bentuk sampel pola suara kutho pengguna Irma

Tabel 6. Nilai maksimal dan minimal koefisien pengguna Dela

\begin{tabular}{cccccc}
\hline Koef & S1 & S2 & S3 & S4 & S5 \\
\hline Max & 6,6475 & 6,4082 & 6,4301 & 8,3164 & 7,7596 \\
Min & $-6,3937$ & $-7,2471$ & $-7,1867$ & $-9,0409$ & $-8,7245$ \\
\hline
\end{tabular}

Gambar 4 sampai 6 menghasilkan bentuk pola yang berbeda untuk setiap pengguna. Perbedaan bentuk pola suara 4 pengguna dapat dilihat pada gambar 8

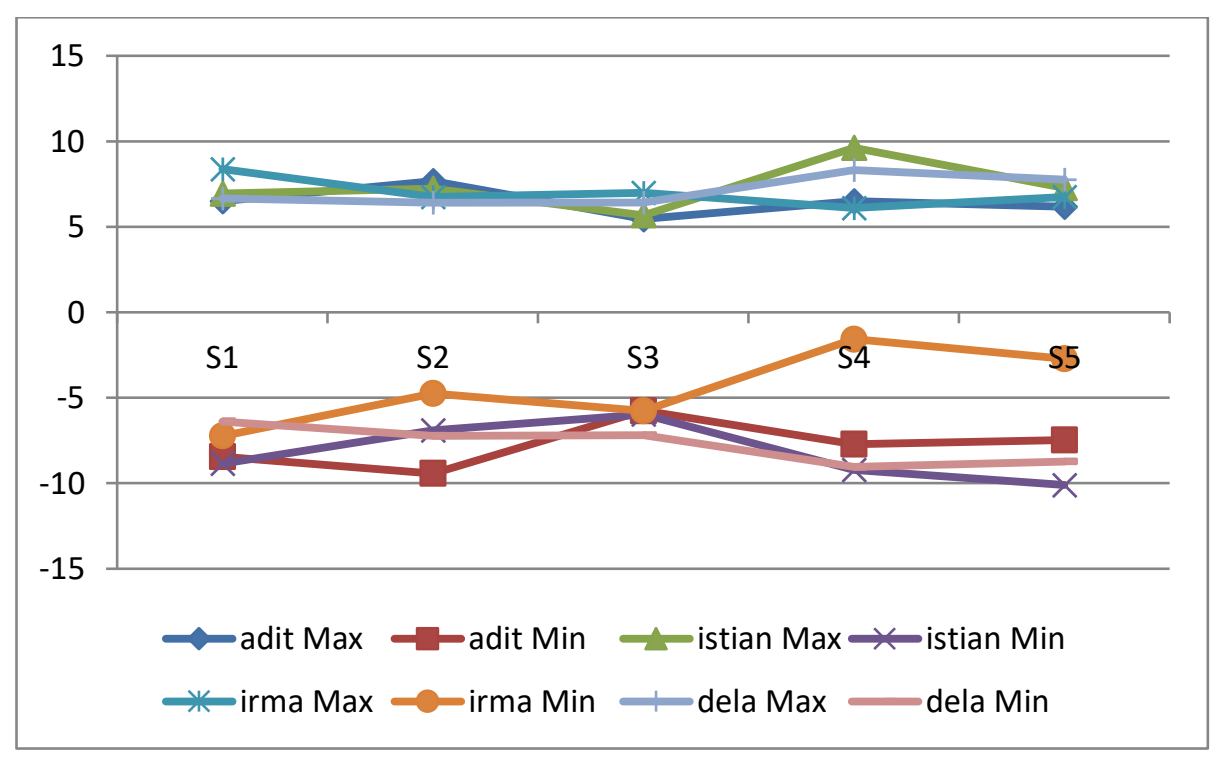

Gambar 6. Grafik Pola Suara 4 Pengguna

Pada gambar 6 pengujian pola suara yang dilakukan oleh 4 pengguna menggunakan MFCC menghasilkan bentuk pola suara yang berbeda

\section{KESIMPULAN}

Mel Frequency Cepstral Coefficients (MFCC) adalah metode yang cocok untuk proses ekstraksi ciri berdasarkan hasil pola yang dihasilkan serta dialek Indonesia juga mempengaruhi pola suara pengucapan bahasa jawa

\section{REFERENCES}

[1] I. Agustina, F. Fauziah, and A. Gunaryati, "Biometrik Pola Suara Dengan Jaringan Saraf Tiruan,” J. Tek. Inform., vol. 9, no. 2, pp. 140-147, 2018 . 
[2] I. N. K. Wardana and I. G. Harsemadi, "Identifikasi Biometrik Intonasi Suara untuk Sistem Keamanan Berbasis Mikrokomputer," J. Sist. Dan Inform., vol. 9, no. 1, pp. 29-39, 2014.

[3] M. Pendidikan, D. A. N. Kebudayaan, and R. Indonesia, "MENTERI PENDIKAN PERATURAN MENTERI PENDIDIKAN DAN KEBUDAYAAN REPUBLIK INDONESIA NOMOR 26 TAHUN 2017,” 2017.

[4] J. Adler, M. Azhar, and S. Supatmi, "Identifikasi Suara dengan MATLAB sebagai Aplikasi Jaringan Syaraf Tiruan Speech Recognition in MATLAB as Artificial Neural Network Application," vol. 1, no. 1, pp. 16-23, 2013.

[5] R. Aisuwarya, K. I. Putri, and M. H. Hersyah, "IMPLEMENTASI SPEECH RECOGNITION SEBAGAI SISTEM KONTROL PADA SMART HOME BERBASIS MIKROKONTROLER MENGGUNAKAN METODE HIDDEN MARKOV MODEL ( HMM ), 2017.

[6] E. Widiyanto, S. N. Endah, and S. Adhy, "APLIKASI SPEECH TO TEXT BERBAHASA INDONESIA MENGGUNAKAN MEL FREQUENCY CEPSTRAL COEFFICIENTS DAN HIDDEN MARKOV MODEL ( HMM )," pp. 39-44, 2014.

[7] R. Bogdan et al., "Kendali Suara Berbahasa Indonesia Untuk Automasi Rumah Tinggal,” vol. 11, no. 1, pp. 1-6, 2018.

[8] R. Firmansyah, E. C. Djamal, R. Yuniarti, J. Informatika, and F. Sains, "Identifikasi Nada Dari Sinyal Suara Alat Musik Instrumen Menggunakan Metode Mel Frequency Cepstrum Coefficients dan Hidden Markov Model,” pp. 7-12, 2018.

[9] J. T. Elektro, U. Brawijaya, and A. Mustofa, "Sistem Pengenalan Penutur dengan Metode Mel-frequency Wrapping," vol. 7, no. 2, pp. 88-96, 2007.

[10] A. R. Darma Putra, "Verifikasi Biometrika Suara Menggunakan Metode MFCC Dan DTW Darma," LONTAR Komput. VOL. 2 NO.1 JUNI 2011, vol. 2, no. 1, pp. 8-21, 2011.

[11] S. Helmiyah, A. Fadlil, A. Yudhana, M. T. Informatika, and U. A. Dahlan, "Pengenalan Pola Emosi Manusia Berdasarkan Ucapan Menggunakan Ekstraksi Fitur Mel-Frequency Cepstral Coefficients ( MFCC ) Speech Based Emotion Pattern Recognition Using Mel- Frequency Cepstral Coefficients (MFCC) Feature Extraction,” vol. 4, no. 2, pp. 372-381, 2018. 